\title{
Analysis on the Influencing Factors of Job Burnout of Nurses in Haikou Tertiary Hospital
}

\author{
Yun Liang1 ${ }^{1}$ Shuping Zhou ${ }^{2}$, Yunsuo Gao², Xiaodan Wang ${ }^{3}$ \\ ${ }^{1}$ Haikou Maternal and Child Health Care Hospital, Haikou, China \\ ${ }^{2}$ Hainan General Hospital, Haikou, China \\ ${ }^{3}$ School of Public Health, Hainan Medical University, Haikou, China \\ Email: ${ }^{* Z S P L J H @ 163 . c o m ~}$
}

How to cite this paper: Liang, Y., Zhou, S.P., Gao, Y.S. and Wang, X.D. (2020) Analysis on the Influencing Factors of Job Burnout of Nurses in Haikou Tertiary Hospital. Open Journal of Nursing, 10, 929-942. https://doi.org/10.4236/ojn.2020.109064

Received: August 9, 2020

Accepted: September 25, 2020

Published: September 28, 2020

Copyright $\odot 2020$ by author(s) and Scientific Research Publishing Inc. This work is licensed under the Creative Commons Attribution International License (CC BY 4.0).

http://creativecommons.org/licenses/by/4.0/ (c) (i) Open Access

\begin{abstract}
Objective: To understand the influencing factors of job burnout among nurses in Haikou 3A hospital and explore its direct and indirect effects, so as to provide a scientific basis for the work efficiency of nursing staff. Methods: Between November 2, 2015 and November 2015, using multi stage random sampling, self-administered questionnaire survey was conducted among 1049 nursing staff, using the path analysis method to study the effect of direct and indirect factors effect. Results: The total score of job burnout of nurses was $38.44 \pm 7.55$, high occupational burnout was $0.9 \%$, moderate occupational burnout was $66.5 \%$, and low occupational burnout was $32.6 \%$. The scores of job burnout were compared among the nurses with different titles, and less achievement $(\mathrm{F}=8.342, \mathrm{P}<0.001)$ and depersonalization $(\mathrm{F}=3.12, \mathrm{P}=$ 0.025) were statistically significant. Nurses' Job Burnout and job stressors were the first, and the canonical correlation coefficient was $0.4397(\mathrm{~F}=20.54$, $\mathrm{P}<0.0001$ ), indicating that the more problems existed in patient care, the greater the degree of emotional exhaustion. The first canonical correlation coefficient of job burnout and job satisfaction of nurses was $0.3791(\mathrm{~F}=12.8$, $\mathrm{P}<0.0001$ ), indicating that the better the family and work balance, the less individualized nurses were. The path analysis results showed that the 4 dimensions of job stressors (management and interpersonal problems) is positive, the direct effect of the strongest (0.219), the total effect of sort of work pressure source of 4 dimensions $(0.245)>5$ dimensions of work pressure source $(0.125)>$ title $(-0.112)$ job satisfaction scores $(-0.097)$. Conclusion: Job stress, job satisfaction and job title are the factors that affect job burnout. The 4 and the direct and indirect effects of job stressors are the strongest, and measures should be taken to solve these problems.
\end{abstract}




\section{Keywords}

Burnout, Canonical Correlation, Path Analysis, Influencing Factors, Nurses

\section{Introduction}

Job burnout is also known as "job exhaustion", "job abathy", "job inertia", "job indifference", etc. [1]. American psychiatrist Freudenberger first proposed the word job burnout in 1974, which is used to describe the phenomenon of physical and emotional exhaustion experienced by people helping professionals in their work environment. Job burnout is a serious negative emotional state in which the service object of the industry individual falls into, and the incidence rate is high among nurses [2] [3] [4] [5]. With the progress of society, the requirements and standards of nurses are constantly improving, which often increases the professional pressure of nurses. Under the influence of these pressures, not only will reduce the enthusiasm of nurses, but also will increase the incidence of nurses' job burnout [6]. According to relevant data reports: the incidence of job burnout of domestic nurses was $62.8 \%$, among which $8.9 \%$ of nurses showed high burnout [7]. In this study, canonical correlation, multiple linear regression and path analysis were used to study the influencing factors of job burnout of nursing staff in tertiary hospitals in Haikou City, and to put forward effective suggestions for alleviating job burnout of nurses in China.

\section{Object and Method}

\subsection{Respondents}

The method of multistage random sampling was used. The first stage: there are 5 Grade-A general hospitals in Haikou City, and 3 hospitals are selected by simple random sampling method. In the second stage, nurses in each hospital were divided into 7 layers: internal, external, gynecology, pediatrics, emergency department, intensive care unit and outpatient department. Inclusion and exclusion criteria: the inclusion criteria were engaged in clinical nursing work, voluntary participation in the research, age $\geq 30$ years old; exclusion criteria were secondment to non nursing positions for more than 5 years.

\subsection{Estimation of Sample Size}

According to the pre-survey, the incidence of nurses' willingness to postpone their retirement was $32.14 \%(18 / 56)$. According to the sample calculation formula of the current survey:

$$
N=\frac{t_{\alpha}^{2} P(1-P)}{\delta^{2}}
$$

With $a=0.05, P=0.32$, and allowable error $\&=0.1 \mathrm{P}$, the required sample size for calculation should be 850 persons. In order to ensure that there are enough 
samples for statistical analysis, the survey was expanded by $10 \%$, and the sample size was finally determined to be $850 \times(1+10 \%)=935$ people.

\subsection{Method}

\subsubsection{Survey Tools}

1) General information questionnaire: including age, gender, professional title, educational background, etc.

2) Nurse work stressor scale: the scale is divided into 5 aspects, with 35 items in total, 7 problems in nursing specialty and work, 5 problems in time distribution and workload [8], 3 problems in working environment and equipment shortage, 11 problems in patient care, and 9 problems in management and interpersonal relationship [9]. Grade 1 to 4 scoring method was used, including mild pressure (1 point), moderate pressure ( 2 points), considerable pressure ( 3 points), and maximum pressure (4 points). The higher the score, the greater the degree of stress [10].

3) Nurses' job satisfaction scale: McCloskey/Mueller satisfaction scale, MMSs) is currently the most widely used and has been proved to have good reliability and validity, including 8 aspects of welfare, scheduling, balance between family and work, relationship between colleagues, social opportunities, opportunities to work part-time, job recognition, professional development and job control and responsibility, with a total of 31 items [11].

4) Nursing burnout scale (NBS): there are three dimensions of emotional exhaustion, depersonalization and less sense of achievement, with 15 items, and the score method of grade 1 to 4 is adopted. The total score of job burnout is the sum of all dimensions. According to Huang Xuefei's job burnout analysis method [12], according to the score, it is divided into high, medium and low, 15 35 for low degree of job burnout, 36 - 55 for moderate job burnout, 56 - 75 for high job burnout.

\subsubsection{Investigator Training and Pre-Investigation}

The investigators have received unified training, unified guidance, mastered the investigation methods, strictly controlled the bias, and carried out the consistency test of the investigators. On November 2, 2015 and November 16, 2015, 56 nurses in a hospital were investigated to test the reliability and validity of the scale, and preliminary analysis was made to increase or decrease the influencing factors. The Cronbach coefficient reliability was 0.958 , split half reliability was 0.824 and repeatability reliability was 0.924 . The Cronbach coefficient reliability was 0.937 , split half reliability was 0.789 , and repeatability reliability was 0.914 . The Cronbach coefficient reliability was 0.764 , split half reliability was 0.750 and repetition reliability was 0.846 . The reliability of the scale is high.

\subsubsection{Data Collection}

Through the coordination of the head nurse of the investigation department, the questionnaire was distributed, and the survey was completed according to the 
requirements, so as to ensure the authenticity and integrity of the questionnaire. It took about 20 minutes to complete by self filling. If more than 5 items are missing, they will be rejected. A total of 1100 questionnaires were sent out, and 1049 valid questionnaires were recovered, with an effective recovery rate of 93.36\%.

\subsection{Statistical Analysis}

Epidata3.0 was used for double entry of data, and spss19.0 software was used for statistical analysis. ANOVA was used to compare the measurement data between the two groups. Canonical correlation analysis was used for multivariate correlation analysis, and multiple linear regression method was used for influencing factor screening. Amos17.0 software was used for path analysis. The inspection level was 0.05 .

\section{Results}

\subsection{General Information of the Research Object}

There were 1049 subjects, 31 males and 1018 females. The ratio of male to female was 3:97. The average age was $37.98 \pm 7.32$ years old and the average nursing age was $17.05 \pm 8.41$ years old. There were 876 nurses $(83.5 \%), 153$ head nurses (14.6\%), and 20 head nurses (1.9\%).

\subsection{The Total Score and Dimension Score of Job Burnout of Nurses in Grade 3 a Hospital of Haikou City}

The total score of job burnout was $38.44 \pm 7.55$. The total score of job burnout was divided into three grades: high burnout was $0.9 \%$ (9/1049), moderate burnout was $66.5 \%$ (696/1049), and low burnout was 32.6\% (342/1049). The scores of each dimension are shown in Table 1.

\subsubsection{Comparison of Total Scores and Scores of Various Dimensions of Nurses' Job Burnout in Different Units}

The analysis of variance was used to compare the scores of various dimensions of job burnout among nurses in different hospitals. The results showed that the total scores and the dimensions of job burnout were statistically significant in the 3 hospitals. The BONF method is used for pairwise comparison, and the results are shown in Table 2.

Table 1. Total score and dimension score of nurses' Job Burnout.

\begin{tabular}{cc}
\hline Dimension & $(\bar{x} \pm s)$ \\
\hline Emotional exhaustion & $20.17 \pm 5.13$ \\
Less sense of achievement & $12.54 \pm 3.83$ \\
De personalization & $5.73 \pm 2.47$ \\
Total score of job burnout & $38.44 \pm 7.55$ \\
\hline
\end{tabular}


Table 2. Comparison of total scores and dimensions of job burnout among nurses in different hospitals.

\begin{tabular}{|c|c|c|c|c|c|c|}
\hline Dimension & $\mathrm{HGH}(\mathrm{n}=391)$ & $\mathrm{HH}(\mathrm{n}=211)$ & $\mathrm{FH}(\mathrm{n}=197)$ & $\operatorname{HAR}(\mathrm{n}=250)$ & $F$ & $P$ \\
\hline Emotional exhaustion & $21.0 \pm 5.03^{\mathrm{b}}$ & $20.41 \pm 5.63^{\mathrm{b}}$ & $19.17 \pm 4.51^{\mathrm{a}}$ & $19.37 \pm 5.06^{\mathrm{a}}$ & 8.766 & $<0.001$ \\
\hline Less sense of achievement & $12.39 \pm 3.78^{\mathrm{a}}$ & $12.44 \pm 3.65^{\mathrm{a}}$ & $13.80 \pm 3.76^{\mathrm{b}}$ & $11.88 \pm 3.91^{\mathrm{a}}$ & 9.880 & $<0.001$ \\
\hline De personalization & $5.73 \pm 2.57^{\mathrm{a}}$ & $5.68 \pm 2.43^{\mathrm{ac}}$ & $6.40 \pm 2.50^{\mathrm{b}}$ & $5.24 \pm 2.23^{\mathrm{c}}$ & 8.002 & $<0.001$ \\
\hline Total score of job burnout & $39.16 \pm 7.41^{\mathrm{b}}$ & $38.53 \pm 8.00^{\mathrm{b}}$ & $39.37 \pm 6.98^{\mathrm{b}}$ & $36.49 \pm 7.48^{\mathrm{a}}$ & 7.874 & $<0.001$ \\
\hline
\end{tabular}

Note 1: 1) Hainan General Hospital (HGH); 2) Haikou hospital (HH); 3) The First Affiliated Hospital of Hainan Medical University (FH); 4) Hainan Agricultural Reclamation hospital (HAR); Note 2: abcstands for different populations, the same letter indicates the same population for each group, and vice versa.

\subsubsection{Comparison of Total Score and Dimension Score of Nurses in Different Work Departments}

The results showed that the total score of job burnout, emotional fatigue and less sense of achievement were statistically significant. The comparison was made by bonf method. The results are shown in Table 3.

\subsubsection{Comparison of Total Score and Dimension Score of Job Burnout among Nurses with Different Professional Titles}

The results showed that the total score of job burnout, less sense of achievement and depersonalization were statistically significant. The bonf method was used for pairwise comparison. The results are shown in Table 4.

\subsubsection{Comparison of the Scores of Job Burnout among Nurses of Different Ages}

The results showed that the total score of job burnout, less sense of achievement and depersonalization were statistically significant. Bonf method was used for pairwise comparison. The results are shown in Table 5.

\subsection{Canonical Correlation Analysis on the Dimensions of Job Burnout, Job Stressors and Satisfaction of Nurses}

\subsubsection{Canonical Correlation Analysis between Job Burnout and Job Stressors in Nurses}

Based on the canonical correlation analysis of three dimensions of burnout scale and five dimensions of job stressor scale, it can be seen from Table 6 that there are three pairs of canonical correlation coefficients. The first canonical correlation coefficient is $0.4397(\mathrm{~F}=20.54, \mathrm{P}<0.0001)$, the contribution rate is $77.83 \%$, the second canonical correlation coefficient is $0.2494(\mathrm{~F}=8.77, \mathrm{P}<0.0001)$, and the contribution rate is $21.53 \%$.

According to Table 7, Table 8, the first pair of canonical correlation variables are

$$
\begin{gathered}
\mathrm{V} 1=0.1531 \mathrm{x} 1+0.3468 \mathrm{x} 2-0.0116 \mathrm{x} 3+0.6127 \mathrm{x} 4+0.0305 \mathrm{x} 5 \\
\mathrm{~W} 1=1.0806 \mathrm{y} 1+0.2673 \mathrm{y} 2-0.4038 \mathrm{y} 3
\end{gathered}
$$

Standardized canonical correlation variables showed that V1 was mainly affected by nursing problems, while W1 was mainly affected by emotional fatigue. 
Table 3. Comparison of total scores and dimensions of job burnout among nurses in different departments.

\begin{tabular}{|c|c|c|c|c|c|c|c|c|c|c|}
\hline Dimension & $\begin{array}{l}\text { Internal } \\
\text { medicine } \\
(\mathrm{n}=263)\end{array}$ & $\begin{array}{c}\text { Surgery } \\
(\mathrm{n}=245)\end{array}$ & $\begin{array}{l}\text { Gynecology } \\
\quad(\mathrm{n}=63)\end{array}$ & $\begin{array}{l}\text { Pediatrics } \\
(\mathrm{n}=53)\end{array}$ & $\begin{array}{l}\text { Emergency } \\
\qquad(\mathrm{n}=71)\end{array}$ & $\begin{array}{c}\text { ICU } \\
(n=63)\end{array}$ & $\begin{array}{l}\text { Outpatient } \\
(\mathrm{n}=149)\end{array}$ & $\begin{array}{c}\text { Other } \\
\text { departments } \\
(\mathrm{n}=190)\end{array}$ & $F$ & $P$ \\
\hline $\begin{array}{l}\text { Emotional } \\
\text { exhaustion }\end{array}$ & $\begin{array}{c}20.57 \pm \\
5.04^{\mathrm{ac}}\end{array}$ & $\begin{array}{c}19.78 \pm \\
4.99^{\mathrm{a}}\end{array}$ & $\begin{array}{l}20.74 \pm \\
5.24^{\mathrm{abc}}\end{array}$ & $\begin{array}{c}19.49 \pm \\
5.25^{\mathrm{a}}\end{array}$ & $\begin{array}{c}21.51 \pm \\
5.93^{c}\end{array}$ & $\begin{array}{c}21.54 \pm \\
5.16^{\mathrm{c}}\end{array}$ & $\begin{array}{c}19.62 \pm \\
4.89^{\mathrm{a}}\end{array}$ & $\begin{array}{c}19.40 \pm \\
4.98^{\mathrm{ab}}\end{array}$ & 2.738 & 0.008 \\
\hline $\begin{array}{l}\text { Less sense of } \\
\text { achievement }\end{array}$ & $\begin{array}{c}12.79 \pm \\
3.68^{\mathrm{a}}\end{array}$ & $\begin{array}{c}12.69 \pm \\
4.13^{\mathrm{a}}\end{array}$ & $\begin{array}{c}13.16 \pm \\
3.76^{\mathrm{a}}\end{array}$ & $\begin{array}{c}12.34 \pm \\
3.86^{\mathrm{ab}}\end{array}$ & $\begin{array}{c}13.21 \pm \\
3.97^{\mathrm{a}}\end{array}$ & $\begin{array}{c}13.24 \pm \\
3.68^{\mathrm{a}}\end{array}$ & $\begin{array}{l}11.64 \pm \\
3.51^{\mathrm{b}}\end{array}$ & $\begin{array}{l}11.89 \pm \\
3.69^{\mathrm{b}}\end{array}$ & 2.876 & 0.006 \\
\hline De personalization & $\begin{array}{l}5.85 \pm \\
2.45^{\mathrm{a}}\end{array}$ & $\begin{array}{c}5.73 \pm \\
2.44^{\mathrm{a}}\end{array}$ & $\begin{array}{l}6.63 \pm \\
2.79^{\mathrm{b}}\end{array}$ & $\begin{array}{c}5.47 \pm \\
2.88^{\mathrm{a}}\end{array}$ & $\begin{array}{c}5.65 \pm \\
2.99^{\mathrm{a}}\end{array}$ & $\begin{array}{c}5.42 \pm \\
1.81^{\mathrm{a}}\end{array}$ & $\begin{array}{l}5.63 \pm \\
2.27^{\mathrm{a}}\end{array}$ & $\begin{array}{c}5.46 \pm \\
2.37^{\mathrm{a}}\end{array}$ & 1.797 & 0.084 \\
\hline $\begin{array}{l}\text { Total score of } \\
\text { job burnout }\end{array}$ & $\begin{array}{c}39.21 \pm \\
7.06^{\mathrm{a}}\end{array}$ & $\begin{array}{l}38.20 \pm \\
7.40^{\text {abde }}\end{array}$ & $\begin{array}{l}40.53 \pm \\
7.64^{\text {ace }}\end{array}$ & $\begin{array}{l}37.30 \pm \\
7.83^{\mathrm{abd}}\end{array}$ & $\begin{array}{l}40.37 \pm \\
7.79^{\text {ace }}\end{array}$ & $\begin{array}{c}40.20 \pm \\
7.59^{\mathrm{ae}}\end{array}$ & $\begin{array}{l}36.89 \pm \\
7.53^{\mathrm{b}}\end{array}$ & $\begin{array}{c}36.75 \pm \\
7.77^{\mathrm{b}}\end{array}$ & 4.448 & $<0.001$ \\
\hline
\end{tabular}

Note: ${ }^{a b c d e}$ stands for different populations, the same letter means the same population in each group, and vice versa.

Table 4. Comparison of total score and dimension score of job burnout of nurses with different professional titles.

\begin{tabular}{|c|c|c|c|c|c|c|}
\hline Dimension & $\begin{array}{l}\text { Nurses } \\
(\mathrm{n}=91)\end{array}$ & $\begin{array}{l}\text { Nurses } \\
(\mathrm{n}=364)\end{array}$ & $\begin{array}{l}\text { Nurses in charge } \\
\qquad(\mathrm{n}=476)\end{array}$ & $\begin{array}{c}\text { Assistant Supervisor } \\
\text { or above }(\mathrm{n}=116)\end{array}$ & $F$ & $P$ \\
\hline Less sense of achievement & $12.45 \pm 3.52^{\mathrm{a}}$ & $13.15 \pm 3.69^{\mathrm{ac}}$ & $12.42 \pm 3.80^{\mathrm{ad}}$ & $11.17 \pm 4.21^{\mathrm{b}}$ & 8.342 & $<0.001$ \\
\hline De personalization & $6.23 \pm 2.67^{\mathrm{ac}}$ & $5.83 \pm 2.40^{\mathrm{b}}$ & $5.67 \pm 2.45^{\mathrm{acd}}$ & $5.24 \pm 2.50^{\mathrm{abc}}$ & 3.120 & 0.025 \\
\hline Total score of job burnout & $39.80 \pm 7.40^{\mathrm{a}}$ & $39.35 \pm 7.13^{\mathrm{a}}$ & $38.03 \pm 7.65^{\mathrm{b}}$ & $36.13 \pm 7.91^{\mathrm{c}}$ & 6.958 & $<0.001$ \\
\hline
\end{tabular}

Note: abcdstands for different populations, the same letter indicates the same population in each group, and vice versa.

Table 5. Comparison of total scores and dimensions of job burnout among nurses of different ages.

\begin{tabular}{|c|c|c|c|c|c|c|}
\hline Dimension & $\begin{array}{c}20-29 \\
(n=70)\end{array}$ & $\begin{array}{c}30-39 \\
(\mathrm{n}=532)\end{array}$ & $\begin{array}{c}40-49 \\
(n=347)\end{array}$ & $\begin{array}{c}50 \text { above } \\
(\mathrm{n}=98)\end{array}$ & $F$ & $P$ \\
\hline Emotional exhaustion & $20.65 \pm 5.03^{\mathrm{a}}$ & $20.42 \pm 5.16^{\mathrm{a}}$ & $19.90 \pm 5.17^{\mathrm{a}}$ & $19.47 \pm 4.77^{\mathrm{a}}$ & 1.559 & 0.198 \\
\hline Less sense of achievement & $12.43 \pm 3.27^{\mathrm{abc}}$ & $13.05 \pm 3.76^{\mathrm{a}}$ & $12.04 \pm 3.93^{\mathrm{bc}}$ & $11.56 \pm 3.83^{b c}$ & 7.382 & $<0.001$ \\
\hline Total score of job burnout & $39.38 \pm 7.22^{\mathrm{a}}$ & $39.31 \pm 7.27^{\mathrm{a}}$ & $37.44 \pm 7.80^{\mathrm{b}}$ & $36.53 \pm 7.65^{\mathrm{b}}$ & 6.938 & $<0.001$ \\
\hline
\end{tabular}

Note: ${ }^{a b c}$ stands for different populations, the same letter means the same population in each group, and vice versa.

Table 6. Typical correlation coefficient between job burnout and job stressors.

\begin{tabular}{|c|c|c|c|c|c|}
\hline $\begin{array}{c}\text { Canonical correlation } \\
\text { coefficient }\end{array}$ & $\begin{array}{l}\text { Corrected canonical } \\
\text { correlation coefficient }\end{array}$ & $\begin{array}{l}\text { Approximate } \\
\text { standard error }\end{array}$ & $\begin{array}{l}\text { The square of canonical } \\
\text { correlation coefficient }\end{array}$ & $F$ & $P$ \\
\hline 0.4397 & 0.4339 & 0.0249 & 0.1933 & 20.54 & $<0.0001$ \\
\hline 0.2494 & 0.2436 & 0.0289 & 0.0622 & 8.77 & $<0.0001$ \\
\hline 0.0443 & 0.0236 & 0.0308 & 0.0019 & 0.68 & 0.5616 \\
\hline
\end{tabular}


Table 7. Normalized V typical variable coefficients.

\begin{tabular}{cccc}
\hline Factor & V1 & V2 & V3 \\
\hline Problems in nursing profession and work (X1) & 0.1531 & 0.3269 & -0.7662 \\
Time allocation and workload (X2) & 0.3468 & -0.5776 & -0.6207 \\
Working environment and equipment problems (X3) & -0.0116 & 0.0994 & -0.1515 \\
Problems in patient care (X4) & 0.6127 & -0.6410 & 1.1602 \\
Management and interpersonal issues (X5) & 0.0305 & 1.1582 & 0.1642 \\
\hline
\end{tabular}

Table 8. Normalized w typical variable coefficients.

\begin{tabular}{cccc}
\hline Factor & W1 & W2 & W3 \\
\hline Emotional exhaustion (Y1) & 1.0806 & -0.1042 & 0.0976 \\
Less sense of achievement (Y2) & 0.2673 & 0.4370 & -0.8856 \\
De personalization (Y3) & -0.4038 & 0.8601 & 0.5571 \\
\hline
\end{tabular}

This shows that there is a close relationship between the nursing problems in the indicators of work stressors and emotional exhaustion in the indicators of job burnout.

The second pair of canonical correlation variables were

$$
\begin{gathered}
\mathrm{V} 2=0.3269 \mathrm{x} 1-0.5776 \mathrm{x} 2+0.0994 \times 3-0.6414 \mathrm{x} 4+1.1582 \times 5 \\
\mathrm{~W} 2=-0.1042 \mathrm{y} 1+0.4370 \mathrm{y} 2+0.8601 \mathrm{y} 3
\end{gathered}
$$

Standardized canonical correlation variables showed that V2 was mainly affected by management and interpersonal problems, while W2 was mainly affected by depersonalization. This shows that there is a close relationship between the management and interpersonal problems in job stressors and depersonalization in job burnout indicators.

\subsubsection{Canonical Correlation Analysis between Job Burnout and Job Satisfaction of Nurses}

The canonical correlation analysis of three dimensions of job burnout scale and eight dimensions of job satisfaction scale showed that there were three pairs of canonical correlation coefficients. The first canonical correlation coefficient was $0.3791(\mathrm{~F}=12.8, \mathrm{P}<0.0001)$, the contribution rate was $55.58 \%$, the second canonical correlation coefficient was $0.3374(\mathrm{~F}=9.7, \mathrm{P}<0.0001)$, and the contribution rate was $42.54 \%$ (Table 9).

According to Table 10, Table 11, the first pair of canonical correlation variables are

$$
\begin{gathered}
\mathrm{V} 1=0.1803 \mathrm{cf} 1-0.3525 \mathrm{cf} 2-0.2884 \mathrm{cf} 3+0.4552 \mathrm{cf} 4-0.3588 \mathrm{cf} 5 \\
-0.3196 \mathrm{cf} 6+0.3161 \mathrm{cf} 7+0.6764 \mathrm{cf} 8 \\
\mathrm{~W} 1=-0.3969 \mathrm{y} 1+0.3685 \mathrm{y} 2+0.9241 \mathrm{y} 3
\end{gathered}
$$


Table 9. Typical correlation coefficient between job burnout and job stressors.

\begin{tabular}{cccccc}
\hline $\begin{array}{c}\text { Canonical } \\
\text { correlation } \\
\text { coefficient }\end{array}$ & $\begin{array}{c}\text { Corrected } \\
\text { canonical } \\
\text { correlation } \\
\text { coefficient }\end{array}$ & $\begin{array}{c}\text { Approximate } \\
\text { standard error }\end{array}$ & $\begin{array}{c}\text { The square of } \\
\text { canonical } \\
\text { correlation } \\
\text { coefficient }\end{array}$ & F & P \\
\hline 0.3791 & 0.3624 & 0.0264 & 0.1437 & 12.80 & $<0.0001$ \\
0.3374 & 0.3368 & 0.0273 & 0.1138 & 9.70 & $<0.0001$ \\
0.0752 & 0.0447 & 0.0307 & 0.0056 & 0.99 & 0.4328 \\
\hline
\end{tabular}

Table 10. Normalized V typical variable coefficients.

\begin{tabular}{|c|c|c|c|}
\hline Factor & V1 & $\mathrm{V} 2$ & V3 \\
\hline $\begin{array}{l}\text { Professional development opportunities and } \\
\text { work control and responsibility (Cf1) }\end{array}$ & 0.1803 & 0.0452 & 0.4663 \\
\hline Satisfaction with scheduling (Cf2) & -0.3525 & 0.1588 & -0.7801 \\
\hline Benefits (Cf3) & -0.2884 & 0.168 & -0.5174 \\
\hline Social Opportunity (Cf4) & 0.4552 & 0.1475 & -0.1237 \\
\hline $\begin{array}{l}\text { Relationship between colleagues and } \\
\text { management mode (Cf5) }\end{array}$ & -0.3588 & 0.1647 & 0.8556 \\
\hline Work is approved (Cf6) & -0.3196 & 0.4642 & -0.0745 \\
\hline Opportunity to work part-time (Cf7) & 0.3161 & 0.0475 & 0.0977 \\
\hline Family and work balance (Cf8) & 0.6764 & 0.2248 & 0.1557 \\
\hline
\end{tabular}

Table 11. Normalized w typical variable coefficients.

\begin{tabular}{cccc}
\hline Factor & W1 & W2 & W3 \\
\hline Emotional exhaustion (Y1) & -0.3969 & -0.8659 & 0.5299 \\
Less achievement (Y2) & 0.3685 & -0.7279 & -0.6173 \\
Depersonalization (Y3) & 0.9241 & 0.3963 & 0.4496 \\
\hline
\end{tabular}

Standardized canonical correlation variables showed that V1 was mainly affected by family and work balance, while W1 was mainly affected by depersonalization. This shows that there is a close relationship between the balance of sick family and work in job satisfaction index and depersonalization in job burnout index.

The second pair of canonical correlation variables were

$$
\begin{gathered}
\mathrm{V} 2=0.0452 \mathrm{cf} 1+0.1588 \mathrm{cf} 2+0.1680 \mathrm{cf} 3+0.1475 \mathrm{cf} 4+0.1647 \mathrm{cf} 5 \\
+0.4642 \mathrm{cf} 6+0.0475 \mathrm{cf} 7+0.2248 \mathrm{cf} 8 \\
\mathrm{~W} 2=-0.8659 \mathrm{y} 1-0.7279 \mathrm{y} 2+0.3963 \mathrm{y} 3
\end{gathered}
$$

Standardized canonical correlation variables showed that V2 was mainly af- 
fected by job recognition, while W2 was mainly affected by emotional exhaustion. This shows that there is a close relationship between job recognition and emotional exhaustion in job burnout.

\subsection{Analysis of Influencing Factors of Nurses' Job Burnout}

\subsubsection{Multiple Linear Regression Analysis}

Taking the total score of job burnout as $y$, the total score of job satisfaction, five dimensions of job stressors, employment status, personal pre tax income, professional title, position, medical trouble or medical violence at work, family property savings and property situation, Hospital: Set subvariables (Hospital 1, Hospital 2, Hospital 3); Departments: Set independent variables (Department 1, Department 2, Department 3, Department 4, Department 5, Department 6). The multiple linear regression analysis was conducted by the entry method and the step-by-step method. The factors entering the regression equation included hospital 1, hospital 2, hospital 3, department 3, management and interpersonal problems, professional title, total score of job satisfaction, and problems in patient care. The results are shown in Table 12.

Table 12. Multiple linear regression analysis of job burnout of nurses in grade three hospitals in Haikou City.

\begin{tabular}{|c|c|c|c|c|c|}
\hline Factor & B & $\begin{array}{c}\text { Standard } \\
\text { error }\end{array}$ & Beta & $t$ & $P$ \\
\hline Intercept & 33.270 & 2.151 & & 15.465 & $<0.001$ \\
\hline Hospital 1 & 2.717 & 0.581 & 0.174 & 4.674 & $<0.001$ \\
\hline Hospital 2 & 2.032 & 0.661 & 0.108 & 3.074 & 0.002 \\
\hline Hospital 3 & 3.249 & 0.681 & 0.168 & 4.773 & $<0.001$ \\
\hline Department 1 & 0.996 & 0.609 & 0.057 & 1.636 & 0.102 \\
\hline Department 2 & 0.432 & 0.614 & 0.024 & 0.704 & 0.481 \\
\hline Department 3 & 2.246 & 0.965 & 0.071 & 2.328 & 0.020 \\
\hline Department 4 & -1.214 & 1.051 & -0.035 & -1.156 & 0.248 \\
\hline Department 5 & 1.780 & 0.932 & 0.059 & 1.909 & 0.057 \\
\hline Department 6 & 1.080 & 0.994 & 0.034 & 1.087 & 0.277 \\
\hline Management and interpersonal issues & 0.213 & 0.043 & 0.197 & 4.956 & $<0.001$ \\
\hline Title & -0.988 & 0.273 & -0.105 & -3.614 & $<0.001$ \\
\hline Nursing problems & 0.100 & 0.061 & 0.065 & 1.647 & 0.100 \\
\hline Total score of job satisfaction & -0.033 & 0.014 & -0.080 & -2.371 & 0.018 \\
\hline Problems in patient care & 0.080 & 0.039 & 0.084 & 2.025 & 0.043 \\
\hline
\end{tabular}




\subsubsection{Path Analysis of Job Burnout among Nurses in the Top Three Hospitals in Haikou City}

Based on the above factor analysis, combined with professional knowledge, take the total score of job burnout and the total score of job satisfaction as endogenous variables. Work stressor dimension 4 (management and interpersonal problems), work stressor dimension 5 (patient care Question), the job title is used as an exogenous variable, a path model is established, and the ML method is used to estimate the model parameters. According to the model correction index (MI), the final model is shown in Figure 1. All factors in the model are statistically significant. The model's $\chi^{2}=6.608, \mathrm{P}=0.086>0.05, \mathrm{CMIN} / \mathrm{DF}=2.203<5$, standard RMR $=0.0271$, RSEMA $=0.034<=0.05$, model fit is good, model fit index GFI $=0.997$, adjusted fit index AGFI $=0.987$; comparative fit index CFI $=$ 0.996; standard fit index NFI $=0.993$; value-added fit index IFI $=0.996$, relative fit index RFI $=0.997$, the above indicators are all greater than 0.9 and close to 1 , indicating that the model fits well.

Combined with Figure 1 and Table 13, it can be seen that among the direct effects on job burnout, job stressor dimension 4 has the strongest effect, and its direct effect value is 0.219 . The order of direct effects is job stressor dimension 4 (0.219), professional title $(-0.112)$, job stressor dimension 5 (0.105), and total job satisfaction score $(-0.097)$. The total effect of job stressor dimension 4 on job burnout was the strongest, with the total effect value of 0.245 . The order of total effect was job stressor dimension 4 (0.245), job stressor dimension 5 (0.125), professional title $(-0.112)$, and total score of job satisfaction $(-0.097)$. The total score of job satisfaction and job title only play a direct role in job burnout, while job stressor dimension 5 and job stressor dimension 4 also play an indirect role in job burnout through the total score of job satisfaction.

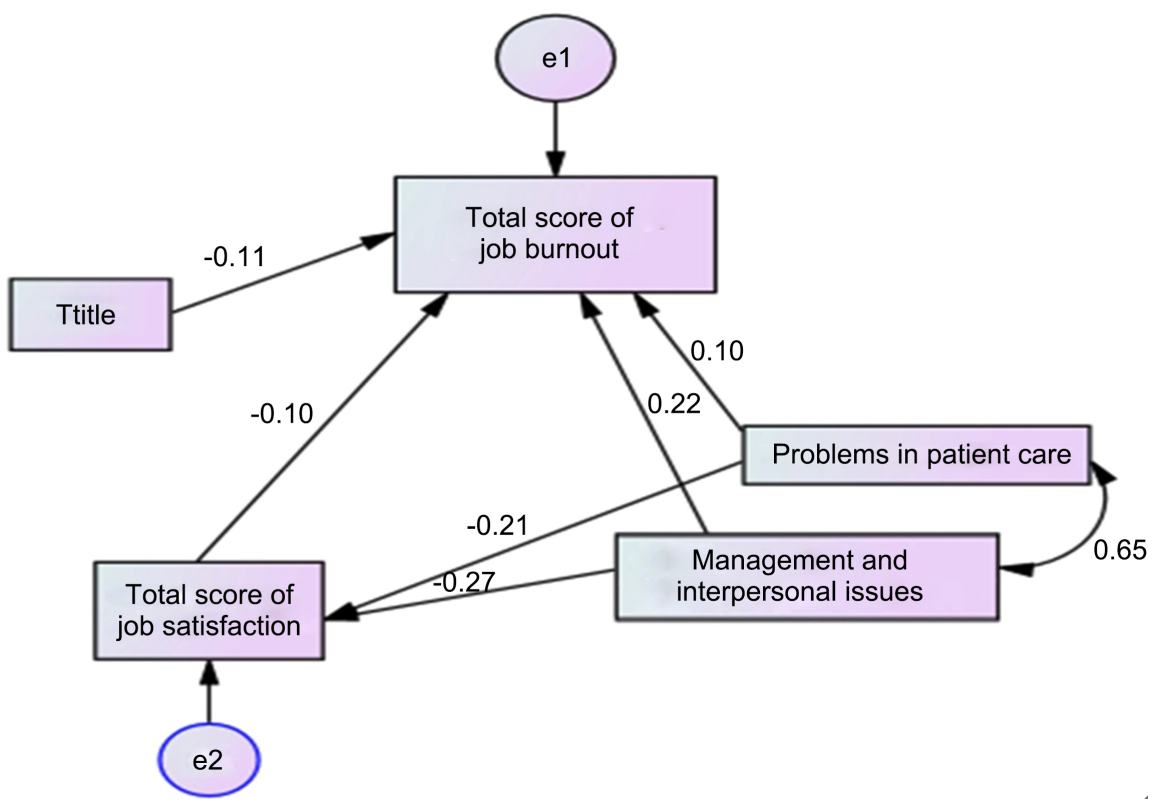

Figure 1. Path analysis chart of job burnout, job stressors and job satisfaction of nurses in grade three hospitals of Haikou City. 
Table 13. Effects of variables.

\begin{tabular}{ccccccc}
\hline Variable & Total effect & Sort & $\begin{array}{c}\text { Direct } \\
\text { effect }\end{array}$ & Sort & $\begin{array}{c}\text { Indirect } \\
\text { effect }\end{array}$ & Sort \\
\hline Title & -0.112 & 3 & -0.112 & 2 & 0 & 3 \\
Nursing problems & 0.125 & 2 & 0.105 & 3 & 0.02 & 2 \\
Total score of job satisfaction & 0.245 & 1 & 0.219 & 1 & 0.026 & 1 \\
Problems in patient care & -0.097 & 4 & -0.097 & 4 & 0 & 3 \\
\hline
\end{tabular}

\section{Discussion}

The results showed that the total score of nurses' job burnout was $38.44 \pm 7.55$, high job burnout was $0.9 \%$, moderate job burnout was $66.5 \%$, low job burnout was $32.6 \%$, which was different from Huang Xuefei's. There are differences in the level of job burnout among different hospitals, which is consistent with the survey results of Wang Xia [13], which may be related to the size of the hospital and the number of patients. The larger the scale, the larger the number of patients, the higher the level of job burnout. The level of job burnout of nurses in different departments is different, which is consistent with the survey results of he Shuyun [14], which may be related to the number of patients accepted by different departments and the severity of patients' illness. There are differences in job burnout among nurses with different professional titles, which is consistent with the survey results of Wu Dequan [15]. This may be related to the psychological endurance of nurses with different professional titles and the workload and responsibilities borne by individuals. The psychological bearing capacity of nurses is weak. The nurses and the Deputy chief nurses and above have undergone various professional training and have strong ability and psychological endurance. Professional titles not only encourage nurses to be positive, mobilize their enthusiasm, but also promote the improvement of nurses' professional level and skills, which is an important influencing factor of job burnout. The level of job burnout among nurses of different ages is different, which is consistent with the survey results of Tao Xiuping [16]. The level of job burnout of nurses decreases with the increase of age, and the level of job burnout of young nurses is the highest. This may be related to the psychology of young nurses. Young nurses are different from older nurses, and they do not want to stay in the profession for a long time and are not sufficient Patience.

The results of canonical correlation model showed that the first canonical correlation coefficient was 0.4397 , the second canonical correlation coefficient was $0.2494, \mathrm{~V} 1$ and $\mathrm{W} 1$ were mainly affected by nursing problems and emotional fatigue, V2 and W2 were mainly affected by management and interpersonal problems and depersonalization.

The results of canonical correlation model between job burnout and job satisfaction showed that the first canonical correlation coefficient was 0.3791 , the second canonical correlation coefficient was $0.3374, \mathrm{~V} 1$ and $\mathrm{W} 1$ were mainly af- 
fected by the balance and depersonalization of family and work, V2 and W2 were mainly affected by job recognition and emotional fatigue, which showed that the balance between family and work was closely related to depersonalization, and positively correlated with work Recognition is closely related to emotional exhaustion and negatively correlated.

The results of path analysis showed that the factors influencing nurses' job burnout were job stressor dimension 4 , job stressor dimension 5 , job title and job satisfaction. Job stressor dimension 4 and job stressor dimension 5 have positive effects on job burnout. First of all, the workload of nurses is very heavy. In addition to physical labor and mental labor, nurses have to carry out medical orders and face patients directly every day. However, managers and doctors are extremely busy with their work, and there is little communication with nurses. When problems arise, colleagues act on their own, and patients spend most of their time. There is a lack of time to communicate with each other, so it is difficult to become intimate friends. Secondly, nurses need to be patient and careful. They should be familiar with the use of various medical devices. Moreover, the social status of nursing work is very low. They often have to be called to and fro by patients. As soon as the patients have something to do, the nurses have to go to take care of them immediately. If it is too late, they will be held accountable by their family members. In today's fierce Doctor-patient Conflict, how to deal with the patient's family members is also an issue For nurses' job burnout is an important problem. It can be seen that job stressors are an important factor affecting the occurrence of job burnout of nurses, which is consistent with the research results of $\mathrm{Yu}$ Yanlin [17]. The total score of job satisfaction has a negative effect on job burnout. On the one hand, the welfare of nursing staff is very little, and the professional development opportunities are also very small. On the other hand, because of the particularity of the profession of nurses, it often means that their working hours are not stable. They often have to work shifts. For a period of time, they go to work in the daytime and at night. Moreover, most of the nurses are women. Staying up late is a very important problem for them. The family will also make a mess because of this inverted biological clock, especially for families with children The problem is, whenever there is a mistake or a problem, the nursing manager's understanding and support for the nurse is not enough, and the work of the nurse is difficult to be recognized. The family members of the patient think that it is natural for the nurse to take good care of the patient, and there is no thanks. Once there is a mistake, it is the fault of the nurse. These will aggravate the degree of nurses' job burnout. This is consistent with the investigation results of Ren Yaxin [18], Hua Qing [19], Lai Xiuhua [20].

\section{Conclusion}

Job stressors, job satisfaction and professional titles are the main factors that affect job burnout. More and more nurses are suffering from job burnout due to increasing pressure. The government and management units can take corres- 
ponding measures, such as improving the salary and welfare of nursing staff, organizing more activities, increasing the opportunity to communicate with colleagues, and communicating with other specialties (non Nursing). It is suggested that nursing managers should understand and support nurses, encourage them more, increase the opportunities to participate in nursing research, write and publish articles, improve the professional development opportunities of nursing profession, reasonably allocate working time, try to meet the needs of nurses, create a relaxed working environment and reduce the working pressure of nurses.

\section{Conflicts of Interest}

The authors declare no conflicts of interest regarding the publication of this paper.

\section{References}

[1] Zhang, Y.M., Wang, X., Luo, H.G., Chen, X.M., Song, J.M. and Li, J.M. (2011) A Study on the Relationship between Nurse Job Burnout and Work Stress. Chinese Journal of Health Psychology, No. 4, 421-422.

[2] Li, L., Ruan, H., Jiang, H., Wang, H.F. and Yang, Y.L. (2013) Discussion on the Influencing Factors of Job Burnout among ICU Nurses in 5 Tertiary A General Hospitals in Shanghai. Chinese Nursing Management, No. 11, 48-51.

[3] Tang, Y., Ding, W. and Chen, J.F. (2013) Investigation on Occupational Burnout of Nurses in Tertiary A Hospitals in Ningxia. Qilu Journal of Nursing, No. 24, 4-5.

[4] Fu, G.L. and Chen, W.J. (2013) Study on the Relationship between Night Shifts and Job Burnout of Nurses in Tertiary A Hospitals. Journal of Nurses Training, No. 7, 637-639.

[5] Wu, X.P. (2013) A Survey on the Work Stress and Mental Health of Nurses in the Ward of a Tertiary Hospital. Chinese Medical Guide, No. 36, 293-294.

[6] Wang, L.H., Xi, M.X. and Li, D. (2012) Investigation on Job Burnout of Nurses with Different Technical Titles. Chinese and Foreign Medical, No. 12, 18-19 + 21 .

[7] Hou, H.F., Huang, M.L. and Wen, X.X. (2016) Investigation and Analysis of Related Factors of Clinical Nurses' Job Burnout. General Nursing, No. 34, 3573-3576.

[8] Lin, S.-L., Huang, X.-F. and Zhou, R.-F. (2010) Analysis on the Relationship between Job Burnout and Job Stressors for Nurses. Nursing and Rehabilitation, No. 2, 102-103.

[9] Jiang, Y.Q., Dong, J.T. and Feng, R. (2013) Influence of High-Quality Nursing Service Demonstration Project on Nurses' Work Pressure and Job Burnout. Journal of Hospital Management of the People's Liberation Army, No. 8, 80-82.

[10] Li, C.G., Tian, X.H., Feng, L.N. and Zhang, R. (2014) Research on the Correlation between Work Stress and Coping Style of Nurses in Intensive Care Unit and Job Burnout. Nursing Research, No. 26, 40-41.

[11] Zhu, M. (2014) Investigation and Analysis of Occupational Satisfaction of Nurses in Holistic Nursing Ward with Responsibility System. Chinese Medical Guide, No. 4, 262-263.

[12] Huang, X.F. (2008) Research on the Current Situation and Countermeasures of Nursing Staff Burnout in a Tertiary General Hospital in Shanghai. Fudan University, Shanghai. 
[13] Wang, X. (2006) Correlation Study of Nurse Burnout and Nurse Working Environment in Changsha City. Central South University, Changsha.

[14] He, S.Y. (2016) Influence Factors Investigation Analysis of Nurses, Occupational Burnout in Third Class A Hospital in Iaian Area. Journal of Taishan Medical University, No. 9, 994-997.

[15] Wu, D.Q., Wu, D. and Zhang, M. (2015) Study on the Correlation between Job Burnout of Nurses and Work Stress, Job Satisfaction and Social Support in Newly Opened Hospitals. General Practice Nursing, No. 35, 3529-3532.

[16] Tao, X.P. (2017) Burnout Status of Pre-Hospital Emergency Nurses in Kunshan Emergency Center. China Disaster Relief Medicine, No. 1, 28-31.

[17] Yu, Y.L. (2013) Research on the Relationship between Job Burnout and Job Satisfaction of Nursing Staff. Journal of Traditional Chinese Medicine Management, No. 3, 313-315.

[18] Ren, Y.X., Zhou, Y., Huang, M.L., Chen, L.P. and Mai, L.H. (2015) Study on 1259 Nurses' Job Satisfaction and Its Influencing Factors. Journal of Nursing Management, No. 2, 86-88 + 100 .

[19] Hua, Q. (2014) Research on the Relationship between Nurses' Job Satisfaction and Turnover Intention. Suzhou University, Suzhou.

[20] Lai, X.H., Li, Z.K., Zhu, X.W. and Qi, M. (2015) Descriptive Evaluation of Nurses' Job Satisfaction and Its Influencing Factors in Tertiary Hospitals. Modern Clinical Nursing, No. 1, 57-63. 